\title{
ИНТЕГРАЦИЯ РОССИЙСКИХ ЭКСПОРТНЫХ СЕТЕЙ В ГЛОБАЛЬНЫЕ ЦЕПОЧКИ СОЗДАНИЯ СТОИМОСТИ НА РЫНКЕ ФАРМАЦЕВТИЧЕСКОЙ ПРОДУКЦИИ *
}

\author{
(c) 2021 Мустафина Ольга Николаевна \\ кандидат экономических наук, кафедра инноваций и инвестиций, \\ Казанский (Приволжский) федеральный университет, Россия, Казань \\ E-mail: olgachitalina@gmail.com \\ ORCID 0000-0002-8917-5274
}

Статья посвящена исследованию направлений интеграции российских фармацевтических компаний в цепочки создания стоимости на глобальном рынке фармацевтической продукции. Проведен анализ глубины интеграции отечественной фармацевтики в глобальные цепочки создания стоимости (ГЦСС) и рассмотрены три сценария укрепления конкурентных позиций отечественных производителей на данном отраслевом рынке, включая создание собственных ГЦСС, интеграцию в уже существующие ГЦСС, а также объединение в национальную сеть дистрибьютеров для позиционирования в качестве глобального логистического центра фармацевтической продукции.

Ключевые слова: фармацевтика, глобальная цепочка создания стоимости, экспортная сеть, конкурентоспособность, интеграция, сценарный подход.

Российская Федерация претендует на ключевые позиции в глобальном экономическом пространстве, включая, прежде всего, рынки технологичной продукции. Именно поэтому в качестве системообразующей цели «Сводной стратегии развития обрабатывающей промышленности Российской Федерации до 2024 года и на период до 2035 года» предусмотрено формирование сфер производственной деятельности с высоким экспортным потенциалом, способных конкурировать на глобальных рынках с ведущими мировыми производителями продукции с высокой добавленной стоимостью [7]. Среди приоритетных отраслей развития экспортной деятельности особое место занимает фармацевтика. Так, в соответствии с национальным проектом «Международная кооперация и экспорт», объем экспорта российской фармацевтической продукции должен к 2024 году увеличиться до $\$ 2,6$ млрд. или на $185,7 \%$ по отношению к уровню 2017 года [6]. Между тем, по итогам 2019 г. объем экспорта фармацевтической продукции из России составил $\$ 850$ млн. Очевидно, что достижение столь амбициозных показателей за относительно небольшой промежуток времени требует продуманных действий по выявлению и поддержке наиболее эффективных мер стимулирования экспорта.
В качестве одного из направлений решения данной задачи следует выделить создание российских экспортных сетей и их интеграцию в глобальные цепочки создания стоимости (ГЦСС), поскольку именно формирование распределенных между различными странами сетевых сообществ является одной из доминирующих тенденций глобального экономического развития. Как результат ГЦСС становятся формой взаимовыгодной организации производства как для компании-ядра экспортной сети, так и для периферийных участников сетевого взаимодействия, обеспечивая тем самым эффективное перераспределение издержек, трансфер технологий и расширение рынков сбыта. При этом характеристики получаемых компанией преимуществ от участия в ГЦСС будут существенно зависеть от этапа производственного процесса $[1,10]$, в рамках которого она предполагает вписаться в ее деятельность.

Следует отметить, что согласно статистической информации, отечественный экспорт товаров группы «фармацевтическая продукция» сосредоточен, прежде всего, на таких позициях, как «лекарственные средства, состоящие из смешанных или несмешанных продуктов» (62\%), а также «кровь человеческую; кровь животных; сыворотки иммунные» (29\%). Основными полу-

\footnotetext{
* Исследование выполнено за счет гранта Российского фонда фундаментальных исследований (проект № $20-$ 310-70023)
} 
чателями этой продукции являются Казахстан (17\%), Украина (16\%) и Беларусь (14,5\%) [9].

Для оценки степени участия компаний отечественной фармацевтической отрасли в ГЦСС, проанализируем структуру добавленной стоимости у производимой фармацевтической продукции. К сожалению, к настоящему времени опубликованные данные, раскрывающие источники формирования добавленной стоимости отраслевых товаров ограничиваются лишь 2015 г. Однако, в результате анализа характеристик экспорта было выявлено что, в 2019 г. номенклатура экспортируемых товаров, как и состав стран их импортеров сохранилась в том же составе что и в 2015 г. [8]. В связи с этим, представляется допустимым использование имеющихся данных для формирования обобщенного представления участия фармацевтической отрасли РФ в ГЦСС.

Как следует из анализа данных, представленных на рис. 1, в структуре российского фармацевтического экспорта преобладает промежуточная продукция. Причем, начиная с 2009 г., доля этой продукции практически без изменения сохраняется на уровне около 80\% [3]. Структура источников формирования добавленной стоимости также достаточно стабильна - с 2005 г. доля иностранной добавленной стоимости не превышала $18 \%$.

Согласно данным [4] в 2016 году Россия занимала 20-е место среди стран-экспортеров фармацевтической продукции при доле иностранной добавленной стоимости в экспорте на уровне $17 \%$.

Таким образом, учитывая, что ГЦСС предполагает организацию распределенного производства какой-либо продукции, в котором участвует как минимум две страны, можно сделать вывод о том, что российская фармацевтика в определенной степени уже интегрирована в ГЦСС, поскольку 80\% ее экспорта составляет промежуточная продукция, используемая для дальнейшей переработки в других странах. Если же обратить внимание на источники формирования добавленной стоимости, то можно увидеть, что почти $18 \%$ добавленной стоимости обеспечивается иностранными компаниями, причем 0,22\% приходится на реимпортированную добавленную стоимость. Это говорит о том, что и иностранные компании пусть и в минимальной степени, но все же интегрированы в российское производство фармацевтической продукции.

С точки зрения цели проведения данного исследования, особый интерес представляет анализ структуры импорта фармацевтической продукции. Согласно статистическим данным за 2015 г., соотношение импорта конечной и промежуточной продукции составляло 30\% и 70\% соответственно, причем 35\% импорта промежуточной продукции далее было реэкспортировано [3]. Вообще сам показатель «реэкспорт импортированной промежуточной продукции» для определенной страны демонстрирует объем импорта промежуточных товаров какой-либо отрасли, включенный в валовый экспорт этой страны. Он характеризует объем импорта промежуточной продукции в производстве продукции и услуг для экспорта и соответственно его значение в качестве источника международной конкурентоспособности.

Если обратиться к списку стран-партнеров, то становится видно, что импорт Россией фармацевтической продукции приходится прежде

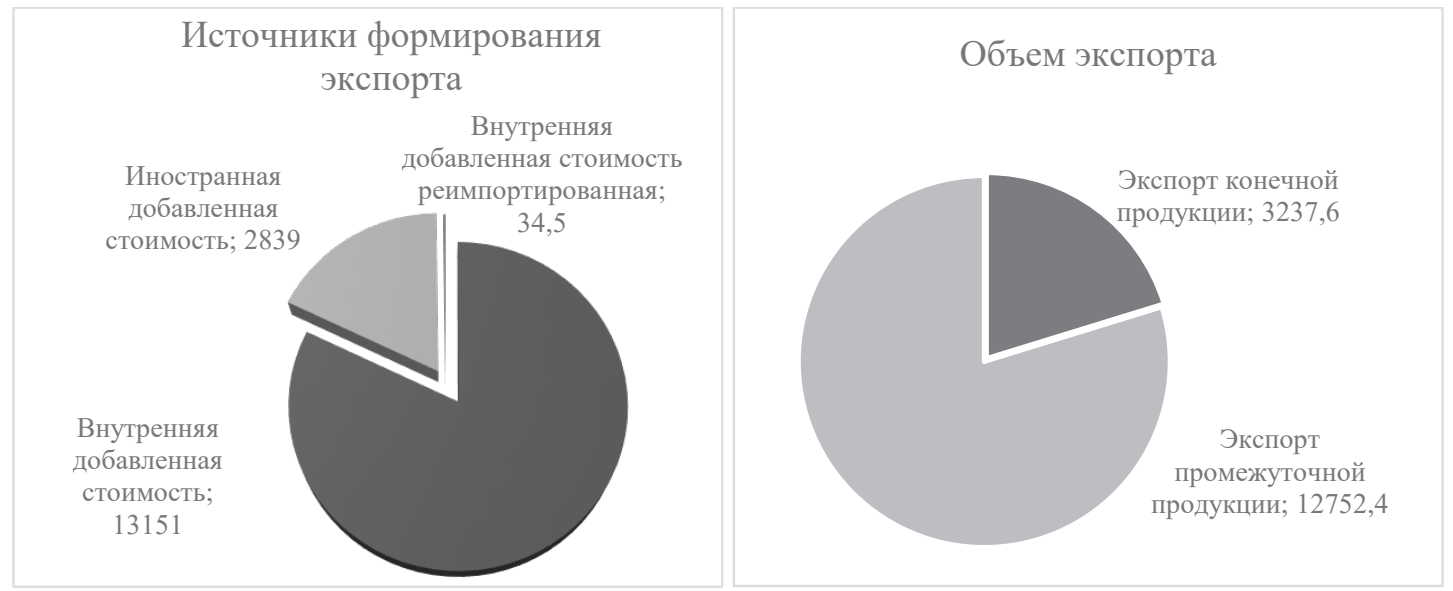

Puc. 1. Структура российского экспорта фармацевтической продукции и источники его формирования в 2015 г., млрд. \$ 
всего на развитые страны, включая Германию, США, Италию, Францию и другие. Российскую же продукцию, как это отмечалось ранее, импортируют в основном страны постсоветского пространства, включая Казахстан, Украину, Беларусь и другие (табл. 1) [9].

Итак, интеграция российских производителей фармацевтической продукции в ГЦСС может преследовать различные цели. Если исходить из того, что важнейшей среди них является увеличение экспорта продукции фармацевтической отрасли до \$2,6 млрд., то интеграция в ГЦСС может проходить по нескольким сценариям.

Первый сценарий основан на предположении о том, что поставленная цель может быть достигнута за счет увеличения экспорта конечной продукции. При такой постановке задачи отечественной экономике имеет смысл участвовать в ГЦСС на компонентном уровне, передавая отдельные стадии производства другим странам. При этом безусловно будет снижаться показатель локализации производства, а показатели объема импорта промежуточной продукции, иностранной добавленной стоимости в объеме экспорта и объем экспорта готовой продукции, напротив, будут расти. Причем для достижения положительного эффекта объем экспорта готовой продукции должен увеличиваться опережающими темпами.

В качестве примера такой интеграции в ГЦСС можно привести производство вакцины «Спутник V», которая имеет спрос как на внутреннем, так и на внешнем рынке. Контракты на ее производство заключены уже с целым рядом стран, включая Индию, Китай, Южную Корею, Бразилия, Египет и ряд других [5]. Во всех странах заказчиком и поставщиком технологий производства является российская компания. Контракты на поставку вакцин из этих стран также заключаются с участием российской стороны.

Второй сценарий интеграции в ГЦСС связан с увеличением объемов экспорта промежуточной продукции. В этом случае необходимо обеспечить конкурентные преимущества промежуточной продукции отечественного производства. Следует отметить, что ее экспорт и так занимает значительную долю в экспорте фармацевтической продукции. Однако, если обратить внимание на данные из таблицы 1 , то можно обнаружить, что основными импортерами российской продукции являются страны ближнего зарубежья при практически полном отсутствии разви-

Таблища 1. Структура импорта и экспорта РФ фармацевтической продукции в 2019 г.

\begin{tabular}{|c|c|c|c|c|c|c|}
\hline & \multicolumn{3}{|c|}{ Импорт } & \multicolumn{3}{|c|}{ Экспорт } \\
\hline № & Страна & Объем & Доля & Страна & Объем & Доля \\
\hline 1 & Германия & $\$ 3.05$ млрд & $21.7 \%$ & Казахстан & \$141 млн & $16.6 \%$ \\
\hline 2 & США & \$1.17 млрд & $8.3 \%$ & Украина & \$132 млн & $15.5 \%$ \\
\hline 3 & Италия & \$998 млн & $7.1 \%$ & Беларусь & $\$ 123$ млн & $14.5 \%$ \\
\hline 4 & Франция & \$991 млн & $7 \%$ & Узбекистан & $\$ 83$ млн & $9.8 \%$ \\
\hline 5 & Швейцария & \$945 млн & $6.7 \%$ & Нигерия & $\$ 28.2$ млн & $3.3 \%$ \\
\hline 6 & Ирландия & $\$ 731$ млн & $5.2 \%$ & Киргизия & $\$ 27.7$ млн & $3.3 \%$ \\
\hline 7 & Индия & \$632 млн & $4.5 \%$ & Латвия & \$26.6 млн & $3.1 \%$ \\
\hline 8 & Англия & $\$ 544$ млн & $3.9 \%$ & Литва & $\$ 24.5$ млн & $2.9 \%$ \\
\hline 9 & Венгрия & \$408 млн & $2.9 \%$ & Азербайджан & \$22.1 млн & $2.6 \%$ \\
\hline 10 & Словения & $\$ 398$ млн & $2.8 \%$ & Южная Корея & \$21.1 млн & $2.5 \%$ \\
\hline 11 & Нидерланды & $\$ 387$ млн & $2.7 \%$ & Молдова & \$20.6 млн & $2.4 \%$ \\
\hline 12 & Австрия & $\$ 376$ млн & $2.7 \%$ & Туркмения & \$19.8 млн & $2.3 \%$ \\
\hline 13 & Испания & $\$ 333$ млн & $2.4 \%$ & Армения & \$13.2 млн & 1.5 \\
\hline 14 & Бельгия & $\$ 250$ млн & $1.8 \%$ & Монголия & \$12.9 млн & $1.5 \%$ \\
\hline 15 & Пуэрто-Рико & $\$ 243$ млн & $1.7 \%$ & Грузия & \$12.6 млн & $1.5 \%$ \\
\hline 16 & Беларусь & \$207 млн & $1.5 \%$ & Таджикистан & \$10.6 млн & $1.2 \%$ \\
\hline 17 & Польша & \$206 млн & $1.5 \%$ & Марокко & \$10.5 млн & $1.2 \%$ \\
\hline 18 & Швеция & \$188 млн & $1.3 \%$ & Абхазия & \$10 млн & $1.2 \%$ \\
\hline 19 & Канада & $\$ 174$ млн & $1.2 \%$ & Ирак & $\$ 8.1$ млн & $1 \%$ \\
\hline 20 & Дания & \$161 млн & $1.1 \%$ & Вьетнам & $\$ 7.5$ млн & $0.9 \%$ \\
\hline
\end{tabular}


тых стран. Причем такая ситуация сохраняется на протяжении всего последнего десятилетия. По этой причине расширение экспорта промежуточной продукции может оказаться достаточно сложной задачей. Ее решение будет связано, во-первых, с оценкой наличия возможностей и ресурсов производства дополнительных объемов промежуточной продукции, а, во-вторых, с оценкой возможностей выхода на рынки развитых стран. Тем не менее, расширение экспорта промежуточной продукции может произойти и благодаря развертыванию производств в других странах по первому сценарию, поскольку любое производство потребует ресурсов в случае их отсутствия в стране базирования.

Третий из рассматриваемых сценариев является развитием второго сценария. Если обратить внимание на рис. 2 , то можно увидеть, что около одной трети импортированных промежуточных товаров в последующем реэкспортируются [3]. Возможно два объяснения сложившейся ситуации. С одной стороны, часть импортированной промежуточной продукции может участвовать в последующем производстве и попадать в экспорт в составе продукции более высокой степени переработки. С другой стороны, часть промежуточной продукции может перепродаваться другим странам и тогда российские компании выступают в качестве посредника.

В связи с этим, можно рассматривать вариант формирования в России глобального логистического центра, который будет способствовать, во-первых, реализации собственной продукции, а, во-вторых, будет оказывать услуги посредника между развитыми странами, которые поставляют в нашу страну фармацевтическую продукцию и развивающимися странами, которые, наоборот, импортируют из нее продукцию. Интересно отметить, что, согласно ряду исследований ГЦСС, именно функции глобального логистического центра, наряду с глобальными центрами исследований и разработок, занимают один из наивысших уровней добавленной стоимости [12].

Таким образом, условия и требования к интеграции в ГЦСС на наш взгляд должны быть гибкими и формироваться в зависимости от поставленных целей и задач. Процесс интеграции в ГЦСС сам по себе не может быть самоцелью, поскольку в этом случае страна может получить низкотехнологичные производства, не способствующие достижению ею существенных конкурентных преимуществ [2, 12]. В тоже время, участие в ГЦСС в настоящее время становится объективной необходимостью, поскольку глобализация не только ускоряет распределение производственных стадий между различными странами, но и ужесточает конкуренции между ними. В этой связи обоснование условий интеграции в ГЦСС, учитывающих отраслевую специфику и накопленный задел в организации производств фармацевтической продукции с высокой добавленной стоимостью, является актуальной задачей, требующей проведения дальнейших исследований.

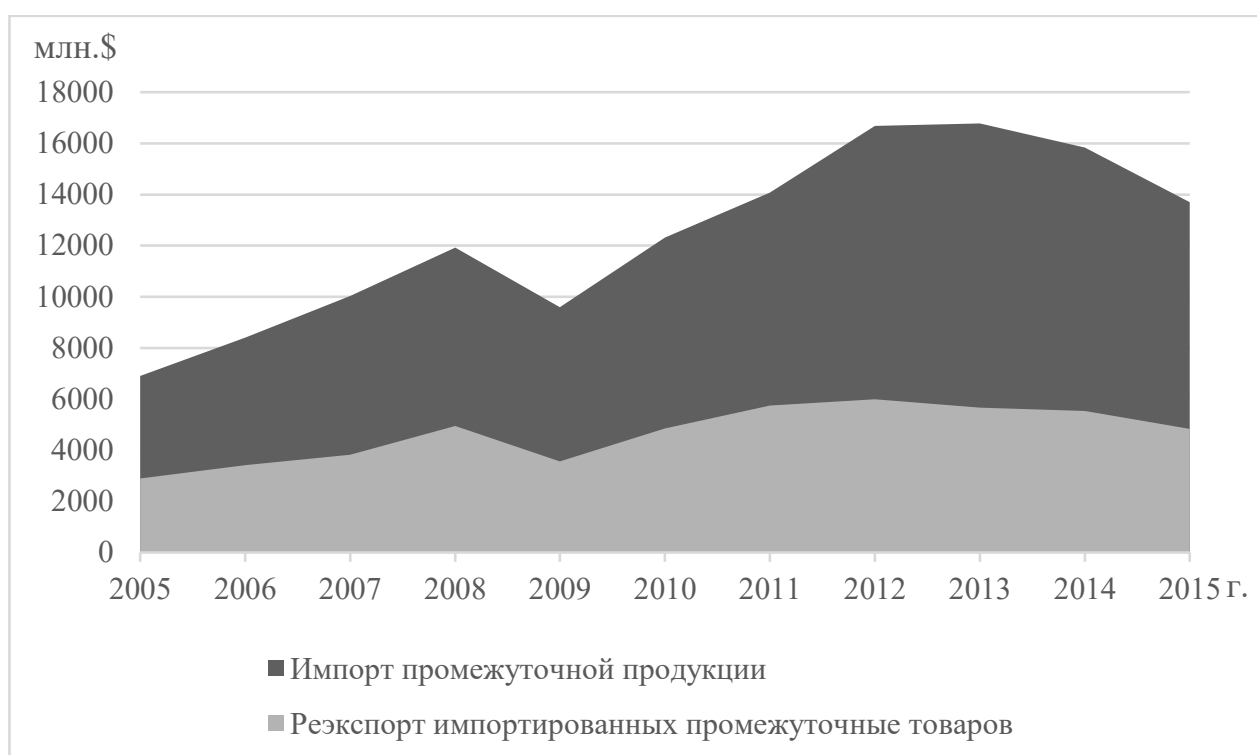

Puc. 2. Соотношение импорта промежуточной продукции и ее реэкспорта в 2015 г. 


\section{Библиографический список}

1. Коновалова, О.Н. Глобальные цепочки создания стоимости в мировой экономике // Инновационная экономика и общество.-2017.- № 2(16).-С. 2-12.

2. Мельник А.Н., Садриев А.Р., Ермолаев К.А., Анисимова Т. Ю., Лукишина Л.В., Мустафина О. Н., Кузьмин М.С. АКТИВИЗАЦИЯ ЭНЕРГОСБЕРЕЖЕНИЯ И ПОВЫШЕНИЯ ЭНЕРГОЭФФЕКТИВНОСТИ В УСЛОВИЯХ ИННОВАЦИОННОЙ МОДЕРНИЗАЦИИ РОССИЙСКОЙ ЭКОНОМИКИ.- Казань: Казанский Федеральный университет. Казань, 2017.- 268 с.

3. Официальный сайт OECD. Режим доступа URL: https://data.oecd.org/

4. Официальный сайт WTO. Режим доступа URL: https://www.wto.org/

5. Официальный сайт НИЦЭМ им. Н. Ф. Гамалеи. Режим доступа URL: https://sputnikvaccine.com/

6. Паспорт национального проекта (программы) «Международная кооперация и экспорт» Режим доступа URL: http://static.government.ru/media/files/FL01MAEp8YVuAkvbZotaYtVKNEKaALYA.pdf

7. Распоряжение Правительства РФ от 6 июня 2020 г. № 1512-р Об утверждении Сводной стратегии развития обрабатывающей промышленности РФ до 2024 г. и на период до 2035 г. Режим доступа URL: https://www. garant.ru/products/ipo/prime/doc/74142592/\#1000 (дата обращения 7.09.2020).

8. Федеральная служба государственной статистики. Режим доступа URL: https://rosstat.gov.ru

9. Федеральная таможенная служба. Режим доступа URL: customs.gov.ru

10. Dedrick J., Kraemer K. L., Linden G. Who Profits from Innovation in Global Value Chains? A Study of the iPod and Notebook OCs. // Industrial and Corporate Change. - 2009.- vol.-19 (1), pp. 81-116

11. Ermolaev K.A., MelnikA.N., Kuzmin M.S. ENERGY EFFICIENCY POLICY ACTIVATING IN RUSSIA BY PROJECT MANAGEMENT METHODS // Revista Publicando. 2017. Vol. 4. no 13. P. 810.

12. Shin, Namchul \& Kraemer, Kenneth \& Dedrick, Jason. Value Capture in the Global Electronics Industry: Empirical Evidence for the "Smiling Curve" Concept // Industry and Innovation - IND INNOV. 2012. T. 19. Pp. 89-107. 